\title{
Preceptor, Supervisor, Tutor e Mentor: Quais são Seus Papéis?
}

\author{
Preceptor, Supervisor, Tutor and Mentor: \\ What are Their Roles?
}

Sérgio Henrique de Oliveira Botti ${ }^{I}$ Sérgio Rego I

\section{PALAVRAS-CHAVE}

- Educação Médica;

- Formação de Conceito;

- Papel Profissional.

\section{KEY WORDS}

- Medical Education;

- Concept Building;

- Professional Role.

Recebido em: 09/04/2007

Reencaminhado em: 03/09/2007

Aprovado em: 12/12/2007

\section{RESUMO}

Sempre houve uma preocupação com a preparação daqueles que cuidam da saúde da população. $\mathrm{Na}$ educação médica, a figura de um profissional experiente, que auxilia na formação, é uma constante. No decorrer dos tempos até hoje, esse profissional vem recebendo diferentes denominações, entre as quais preceptor, supervisor, tutor e mentor. No Brasil, mesmo em documentos oficiais, não ficam claras as funções, intervenções e atividades ligadas a cada um desses termos. Procuramos, então, analisar o significado dessas diferentes denominações usadas pela comunidade científica nacional e internacional. A partir da análise do conceito que cada uma delas expressa, pretendemos construir uma melhor fundamentação das regulações e práticas de ensino-aprendizagem na graduação e pós-graduação em saúde.

\begin{abstract}
The education of those who care for the health of the population has always been a matter of concern. In medical education, the figure of the experienced professional helping to educate and qualify a new generation is a constant finding. Such a professional has been given different names, preceptor, supervisor, tutor and mentor being the most common among them. Even official documents fail to clearly specify which functions, interventions, and activities each denomination entails. We thus aimed to analyze the meaning of these different denominations as used by the national and international scientific communities. Starting with the analysis of the concept each term expresses, we intend to build up a better framework for the regulation and practice of the teaching-learning process in the graduation and postgraduation courses in the health professions.
\end{abstract}


A preocupação com a preparação profissional daqueles que cuidam da saúde da população é uma constante na história da humanidade. Macedo ${ }^{1}$ afirma que, desde a época mais remota, nas tribos primitivas, os candidatos a exercerem a função de pajé eram cuidadosamente selecionados e treinados. Em seus primórdios, como aconteceu com o aprendizado da maioria das ocupações, o ensino da atividade de curar começa de maneira informal, com o treinamento profissional orientado por um prático. Nesse sistema, conforme Mattos², os discípulos aprendiam as habilidades profissionais na relação com seus mestres.

Na história da educação médica, podemos sempre notar a figura de um profissional experiente, que auxilia na formação profissional. Na Europa do século 14, Pádua era considerada o mais importante centro do ensino médico ${ }^{3}$. Nessa escola, para a obtenção do grau de doutor em medicina, era necessário, no mínimo, um ano de prática ao lado de um médico bem conhecido, além de três anos de estudos na faculdade e de outros requisitos. Nos Estados Unidos, em todo o século 18 e por muitas décadas do século 19, o aprendizado e treinamento médicos eram feitos pelos mais jovens estagiando com outros médicos, sendo que a educação formal em escolas médicas era apenas um suplemento desse treinamento ${ }^{4}$. Também no Brasil Colônia, além dos médicos formados em universidades européias, havia aqueles que poderiam praticar a medicina sem a obrigatoriedade de freqüentar qualquer estabelecimento de ensino superior. Nesse sistema, médicos e cirurgiões com diploma universitário eram acompanhados por aprendizes, que tinham um treinamento basicamente centrado na experiência e prática diárias, sem ênfase teórica. Após certo período de acompanhamento e quando eram considerados aptos por seus mestres, esses aprendizes prestavam exames junto às instâncias administrativas e eram licenciados para a pratica médica ${ }^{5}$.

Desde então até os dias atuais, esses profissionais mais experientes que se ocupam da formação médica vêm recebendo diferentes denominações, entre as quais preceptor, supervisor, tutor e mentor. Cada um desses termos significa uma grande variedade de funções, intervenções e atividades ligadas à educação médica, tanto na graduação como na residência ${ }^{6,7-10}$. E a proximidade semântica entre esses nomes pode gerar confusão, de modo a não sabermos ao certo de quem estamos falando e como é definida a função que cada um deles indica ${ }^{7,10}$. A Comissão Nacional de Residência Médica (CNRM), por exemplo, em sua Resolução 005 de $2004^{11}$, referiu-se à função como sendo preceptoria/tutoria. Ou seja, assumiu que há uma equivalência entre as duas denominações.

Neste trabalho, analisamos o significado das diferentes denominações usadas pela comunidade científica nacional e internacional ${ }^{8,9,10,12-20}$ para esta função, procurando entender os pressupostos pedagógicos relacionados com cada um dos termos e avaliando sua pertinência e adequação à função exercida pelo profissional nos diferentes programas de residência. Pesquisamos os termos "preceptor, preceptoria, tutor, tutoria, supervisor, supervisão, mentor e mentoring" em publicações nacionais e internacionais da área da educação de profissionais de saúde e da área médica em geral dos últimos dez anos. Procuramos ainda em outras fontes, como textos históricos, dicionários e documentos oficiais, buscando compreender o sentido dado aos referidos termos nessas fontes. Embora tratemos aqui especificamente do caso da residência médica, nossa reflexão se aplica às residências das demais profissões e às multiprofissionais. $\mathrm{Ou}$ seja, entendendo que cada denominação expressa um conceito, vamos analisá-los de forma a possibilitar uma fundamentação melhor das regulamentações e práticas de ensino-aprendizagem realizadas na graduação e na pós-graduação em saúde.

Temos como objetivo analisar o significado das diferentes denominações dadas à função de acompanhar e orientar os médicos em formação, buscando oferecer subsídios para melhor fundamentação dessa prática.

\section{ENTENDENDO UM CONCEITO}

Um conceito é a representação mental de um objeto, instrumento fundamental do pensamento em sua tarefa de abstrair e generalizar impressões sensoriais, identificar, descrever e classificar os diferentes elementos e aspectos da realidade. É uma construção lógica para simbolizar os fenômenos, criada a partir de impressões, percepções ou experiências complexas, e que só tem sentido dentro de um quadro de referências estabelecido (um sistema teórico, uma teoria). Os conceitos, portanto, não têm significado definitivo, mas são construídos por suas relações com os fatos ${ }^{21,22}$.

Uma análise conceitual tem o papel de apontar as confusões e sobreposições de uso dos termos, bem como sugestões para tentar diminuir as dificuldades de comunicação. Deve ser clara e exige raciocínio preciso sobre o fenômeno e suas interrelações. Mostraremos, então, que conceitos que parecem tão claros e delimitados podem ter várias facetas complexas e freqüentemente contraditórias. E, como resultado final de nossa análise, iremos propor conceitos mais precisos. Esse método consiste em selecionar os conceitos principais, analisar seus elementos significativos, buscar os vários usos do termo, relacionar o fenômeno simbolizado com outros fenômenos semelhantes e, finalmente, verificar o nível de generalização desse conceito ${ }^{22}$.

Chinn e Kramer (1995) apud Lith $^{23}$ consideram que um conceito se situa em um continuum: da experiência mais direta (extremo empírico do conceito) ao mais abstrato dos constructos. Já Rodgers ${ }^{24}$, numa abordagem mais interpretativa e construtivista, está entre aqueles que não usam indicadores empíricos, mas analisam os conceitos de forma holística. Para estes, 
por meio da socialização e repetição de seu uso, um conceito torna-se associado a certos atributos que passam a constituir sua definição. Nesse processo, o desenvolvimento de um conceito tem três fases - significância, uso e aplicação ${ }^{24}$ - que procuraremos observar em nossa reflexão.

Como estamos em um país periférico, onde muitas palavras aqui utilizadas são resultado de traduções, devemos, antes, recordar que as palavras e o mundo mudam juntos, mas não em correlação direta ${ }^{25}$. Quando falamos de fenômenos sociais, culturais e políticos, essa relação entre palavras e o mundo é ainda mais complexa. Pitkin ${ }^{25}$ afirma que os fenômenos são constituídos pela conduta humana, que é formada pelo que as pessoas pensam e dizem, por palavras. Então, os sentidos das palavras, os significados dos conceitos entre povos que falam idiomas diferentes também são diferentes, mas não de um modo que corresponda de forma pura e simples às diferenças semânticas. A história de um conceito exige detalhados relatos paralelos de história verbal e social, política e cultural. Para Or$\mathrm{tiz}^{26}$, a tradução de um conceito de uma língua para outra exige um esforço adicional de interpretação. Ao buscarmos termos equivalentes, não basta simplesmente encontrar o vocábulo adequado, mas considerar toda uma constelação expressiva. Todas essas considerações são importantes para nos ajudar no esclarecimento dos termos que denominam o profissional mais experiente que tem este destacado papel na formação médica.

\section{Preceptor}

Inicialmente, vamos buscar compreender o conceito de preceptor de acordo com seu uso em artigos publicados em periódicos e na legislação brasileira. Para Mills ${ }^{8}$, esse conceito é usado para designar aquele profissional que não é da academia e que tem importante papel na inserção e socialização do recém-graduado no ambiente de trabalho. Ryan-Nicholls ${ }^{27}$, porém, usa o termo para designar o professor que ensina a um pequeno grupo de alunos ou residentes, com ênfase na prática clínica e no desenvolvimento de habilidades para tal prática. Esta função cresce em importância atualmente, pois o ambiente de trabalho está sempre em mudança e exige que o novo profissional constantemente faça adaptações, muitas vezes difíceis, na imagem que tem desse cenário e na bagagem de conhecimentos que traz da graduação. Adquirir experiência clínica constitui uma parte importante da graduação e da pósgraduação, e o preceptor, segundo Bain ${ }^{28}$ e Armitage ${ }^{9}$, tem a função de estreitar a distância entre teoria e prática. Os recémformados chegam ao ambiente de trabalho com certa bagagem de conhecimentos e habilidades, mas deles são exigidas algumas competências consideradas mínimas, nem sempre já adquiridas no processo de formação. O preceptor tem, então, o papel de suporte, para ajudar o novo profissional a adqui- rir prática, até que este tenha maior confiança e segurança em suas atividades diárias $8,10,28-31$.

A palavra preceptor vem do latim praecipio, "mandar com império aos que lhe são inferiores". Era aplicada aos mestres das ordens militares, mas, desde o século XVI (já aparece com este sentido em 1540) é usada para designar aquele que dá preceitos ou instruções, educador, mentor, instrutor. Mais tarde, passou a identificar alguém que educa uma criança ou um jovem, geralmente na casa do educando ${ }^{21}$. Na literatura médica, encontramse diferentes funções para o preceptor, sendo essenciais as de orientar, dar suporte, ensinar e compartilhar experiências que melhorem a competência clínica e ajudem o graduando e o recém-graduado a se adaptar ao exercício da profissão, que, como já dissemos, vive em constante mudança. Para que o profissional possa oferecer cuidado de qualidade em saúde, é necessária completa adesão a essas mudanças. E cabe ao preceptor criar as condições necessárias para que elas sejam implementadas de maneira satisfatória durante o processo de formação".

Houaiss apresenta como significado da palavra preceptoria "prebenda (ocupação rendosa e de pouco trabalho) dada a lentes e magistrados" 21 e nomina a atividade desempenhada pelo preceptor como preceptorado. Entretanto, apesar de ainda não constar do dicionário, preferimos usar a primeira (preceptoria) para designar tal atividade, pois é a palavra consagrada no meio médico e que aparece até mesmo em legislações ${ }^{11}$, podendo, assim, ser entendida como expressão de um conceito.

A principal função do preceptor é ensinar a clinicar, por meio de instruções formais e com determinados objetivos e metas. Portanto, entre as suas características marcantes devem estar o conhecimento e a habilidade em desempenhar procedimentos clínicos. Nesse sentido, o preceptor se preocupa principalmente com a competência clínica ou com os aspectos de ensino-aprendizagem do desenvolvimento profissional, favorecendo a aquisição de habilidades e competências pelos recém-graduados, em situações clínicas reais, no próprio ambiente de trabalho. É importante lembrar, ainda, que as avaliações formais fazem parte também da preceptoria ${ }^{9,32-35}$.

Está claro, então, que o preceptor deve ter a capacidade de integrar os conceitos e valores da escola e do trabalho, ajudando o profissional em formação a desenvolver estratégias factíveis para resolver os problemas cotidianos da atenção à saúde ${ }^{9,36}$. Burke ${ }^{37}$ considera que, pela natureza e extensão das relações desenvolvidas entre os preceptores e os novos profissionais, o preceptor pode ter, além da função de ensinar, as de aconselhar, inspirar e influenciar no desenvolvimento dos menos experientes. Muitas vezes, os preceptores servem de modelo para o desenvolvimento e crescimento pessoal dos recém-graduados e, ainda, auxiliam na formação ética dos novos profissionais durante determinado período de tempo ${ }^{10,28,38-40}$. 
Essas últimas funções do preceptor em muito se assemelham às funções típicas de um mentor e se confundem com elas.

\section{Supervisor}

No dicionário, supervisor (do latim medieval supervisor, pelo inglês supervisor; registrado na língua portuguesa desde 1640) é aquele que dirige, controla, vigia, cuida de tudo e se responsabiliza para que tudo se faça corretamente e de maneira segura ${ }^{21,41}$. No mundo do trabalho, é usado principalmente pela administração e pela engenharia de produção, com foco especial no âmbito das organizações industriais. Segundo Cordeiro $^{42}$, representa todos os níveis de comando na estrutura dessas organizações incumbidos de algum planejamento e controle, que ficam entre a direção e o nível de execução.

Na literatura da área da saúde, o supervisor tem o papel de medir e desenvolver conhecimentos e habilidades de profissionais em início de carreira em seus próprios ambientes clínicos. Ele também deve estimular a aplicação da teoria na prática, desenvolvendo habilidades e ensinando o recém-graduado a utilizar adequadamente o tempo, por meio de priorização de procedimentos e atitudes ${ }^{18}$. Tem, portanto, importante função para melhorar o nível de qualidade da atuação profissional, o que é bom para o próprio profissional e também para o usuário do serviço de saúde. Por isso, alguns autores consideram a supervisão um componente essencial, que marca a boa qualidade do cuidado com a saúde, sendo importante para melhorar o serviço ofertado ao paciente ${ }^{11,43-46}$.

Existem teóricos que levam a ação do supervisor também aos ambientes acadêmicos. Acreditam que a supervisão é importante para a educação médica na pós-graduação e, por extensão, também durante a graduação ${ }^{46,47}$. Grealish e Carrol ${ }^{18}$ diferenciam a supervisão da preceptoria apenas pelo número de recém-formados (ou de alunos da graduação) por professor e pela atividade básica deste. Para esses autores, supervisão ocorre quando existem de seis a oito novos profissionais por professor, que basicamente atua na pesquisa e área acadêmica; já na preceptoria, a relação é de um único recém-formado por professor, um profissional que atua basicamente no serviço de saúde.

Na verdade, a palavra supervisor pode ser usada em várias situações. Existem artigos científicos segundo os quais o supervisor deve exercer papel de modelo, conselheiro e colega, além de saber demonstrar habilidades, ser instrutor, facilitador e, também, saber avaliar. Butterworth (1992) apud Lith $^{23}$ defende que a ação do supervisor pode estar relacionada a uma relação de troca entre profissionais com o objetivo de desenvolver habilidades; Minot (1989) apud $\mathrm{Lith}^{23}$ afirma que a supervisão pode estar ligada a um conceito de revisão da prática profissional e das reações do profissional a seu próprio trabalho; já o United Kingdom Central Council for Nursing Midwifery and
Health Visiting — UKCC (1996) apud Lith ${ }^{23}$ define que o supervisor pode estabelecer, com um recém-graduado, uma relação baseada na prática, demonstrando as próprias habilidades e guiando todo o processo de inserção do neófito.

Ao oferecer suporte, o supervisor estimula o novo profissional no processo de aprendizagem, propiciando-lhe desenvolver seus conhecimentos e competências, e ajudando-o também na construção da autoconfiança ${ }^{23,48,49}$. Nesse conjunto de funções, o conceito de supervisão se relaciona com outros conceitos, como o de prática reflexiva, aconselhamento, formação, suporte, desenvolvimento pessoal e profissional, e também com os conceitos trabalhados neste texto (mentor, preceptor e tutor $)^{23,50}$.

Existem ainda autores que relacionam a ação do supervisor ao processo de decisão em questões éticas e morais da profissão. Esses autores acreditam que a supervisão é necessária não apenas para uma boa prática, sendo essencial também para um bom desenvolvimento moral. Para eles, uma profissão deve oferecer proteção a seus clientes e respaldo no monitoramento de seus próprios modelos e padrões de qualidade da atenção ${ }^{49,50}$. Os desenvolvimentos pessoal e profissional aparecem intrinsecamente relacionados, o que faz com que a personalidade, as crenças e os valores dos supervisores e dos supervisionados tenham grande importância durante o processo de supervisão $o^{23,50,51}$. Assim sendo, o supervisor promove o desenvolvimento da preocupação moral e do perfil profissional, influenciando o processo de tomada de decisões e estimulando a formação da competência e da identidade moral dos jovens profissionais. Estes, com o auxílio da supervisão,adquirem maior autoconfiança e se tornam mais capacitados a estabelecer relações mais autênticas com os pacientes e a assumir maior responsabilidade no cuidado dos $\operatorname{mesmos}^{52-55}$.

Cutcliffe $^{19}$ afirma que há uma diferença no conceito de supervisão entre americanos e europeus. Segundo o autor, na literatura norte-americana, relacionam-se mais com o conceito de supervisor o treinamento de habilidade técnica profissional e a excelência no desempenho dessa habilidade, para que alguém possa exercer a supervisão. Já a literatura européia faz maior aproximação do supervisor com os aspectos pessoais, relacionais e também clínicos do cuidado ao paciente. Para os europeus, é essencial que o supervisor funcione como suporte e seja capaz de proporcionar reflexão sobre a prática diária do profissional de saúde, função muito semelhante à do mentor ${ }^{19,44,56}$.

Mas observar alguém no exercício de determinada atividade, zelar por essa pessoa e ter a certeza de que ela exerce sua atividade são as principais atribuições do supervisor ${ }^{45}$. Essa função, além de levar à adoção de padrões e modelos, leva também à análise de desempenho, o que pode dar ao supervisor um caráter muito formal, punitivo, disciplinar, de imposição e de 
poder $^{11}$. Por isso, há aqueles que não vêem a supervisão como um fator de desenvolvimento profissional e pessoal. Acreditam que é apenas uma imposição de superiores para vigiar, para ver se a atividade está sendo desempenhada corretamente. Para eles, isso contribui para uma conotação negativa da função de supervisionar ${ }^{45,50,57}$. Por isso, para evitar essa depreciação, ensejam que o supervisor seja escolhido entre um dos pares, que não tenha cargos superiores nem detenha maior poder que o jovem profissional, e que tenha habilidades clínicas relevantes, para facilitar o desenvolvimento do supervisionado ${ }^{50}$. Mas questionamos: será que cuidar para que um jovem profissional exerça corretamente suas funções pode ser uma ação vil ou desprezível? Acreditamos, como afirma $\mathrm{Rego}^{5}$, que essa função do supervisor é desejável e tem grande importância.

Ainda sobre o papel do analista de desempenho, observamos que existe uma grande discussão sobre a função da supervisão no desenvolvimento pessoal e profissional do recém-graduado. Esses dois processos de desenvolvimento não acontecem isoladamente, mas são distintos. Distinguir, então, seus aspectos particulares pode ser essencial para compreender melhor o papel do supervisor. Entender desenvolvimento pessoal e profissional como um processo único, sem particularidades, é comprometer a ação do supervisor com mais atribuições do que ela pode realmente abarcar ${ }^{51,56}$.

\section{Tutor}

Vamos nos voltar, agora, para a utilização do termo tutor, para entender seu significado. Nas literaturas americana e européia, tutor designa o professor que se preocupa em ensinar o aluno a "aprender a aprender", principalmente na chamada Aprendizagem Baseada em Problemas (PBL ou ABP). Nesse cenário, o tutor é considerado um guia, um facilitador que auxilia no processo de aprendizagem centrado no aluno ${ }^{58-60}$.

Tutor (do latim tutor, oris) é um termo do direito romano, atribuído àquele que se encarregava de cuidar de um incapaz (como um órfão, por exemplo). Em português, a palavra já era usada no século XIII e tinha o significado de guarda, protetor, defensor, curador; significa também aquele que mantém outras pessoas sob sua vista, que olha, encara, examina, observa e considera; é o que tem a função de amparar, proteger e defender, é o guardião, ou aquele que dirige e governa. Para os ingleses, pode significar um professor para pequenos grupos, que presta atenção especial nesses alunos; e pode significar, ainda, um professor para adultos ou com papel especial na escola $^{21,41}$. Na agricultura, é designação para a estaca que ampara uma planta frágil durante seu crescimento. Como se vê, em qualquer acepção, pertence ao campo semântico da proteção.

Na História do Brasil, temos a presença importante de um tutor: José Bonifácio de Andrada e Silva. Foi nomeado pelo im- perador D. Pedro I, que, após abdicar do trono e partir para a Europa, precisava de alguém para cuidar da formação de seu filho, D. Pedro II. Descreve-se José Bonifácio como um homem de caráter forte e dominador, e, embora seu tutorado tenha sido efêmero, sua figura imponente, acentuada ainda mais pela velhice, exerceu importante influência sobre o príncipe. Considera-se que a presença do tutor e o afastamento dos pais fizeram com que a educação tivesse maior influência na formação do caráter de D. Pedro II do que a hereditariedade ${ }^{61}$. Podemos perceber, então, um exemplo da importância e do papel de um tutor.

$\mathrm{O}$ tutor era uma figura comum nas diversas universidades do Reino Unido. Nesse sistema inglês, o tutor se responsabiliza por ensinar e orientar, tendo o objetivo de zelar pelo cumprimento do programa do curso, além de buscar as metas pessoais do aluno. O tutor orienta, ensina, ajuda na busca de conhecimento e tem também papel importante como avaliador. Pode trabalhar com um aluno individualmente ou com um grupo pequeno de alunos $^{12}$. Nos anos 1960, ainda no Reino Unido, com o estabelecimento de centros de pós-graduação médica, aparece o conceito de tutor clínico; o título é conferido ao profissional que tem a função de coordenar e desenvolver o programa educacional desses centros, identificando as necessidades de treinamento dos alunos, assegurando uma boa aprendizagem, organizando a estrutura da pós-graduação e cuidando da qualidade e da atualização dos professores. Atua principalmente como um advogado dos médicos recém-formados, ajudando-os a buscar seus direitos e a aprimorar sua formação. Mais tarde, no final dos anos 1990, o tutor clínico assume a função de representação dos professores de pós-graduação junto a órgãos centrais do governo e se afasta da luta pela causa dos médicos em treinamento ${ }^{62,63}$.

Hoje, no campo da medicina, denomina-se tutor aquele que orienta a formação de profissionais já graduados e que atuam no sistema de saúde. É a aprendizagem que acontece em ambientes de atenção primária também no Reino Unido. Médicos mais experientes, que prestam esse tipo de atenção à saúde da população, são recrutados por departamentos regionais de pós-graduação para facilitarem a educação permanente. Costumam fazer uma visita semanal e/ou se comunicam por mensagens, discutindo a prática cotidiana com os profissionais no seu próprio ambiente de trabalho ${ }^{64}$. Já na Espanha, também dentro da atenção primária, mas em programa de pós-graduação, existe, durante a residência, a experiência dos tutores de medicina de família e de comunidade. Nesse cenário, o tutor - geralmente um médico mais experiente - além de competência clínica e da capacidade de ajudar a aprender a aprender, precisa ter compreensão da prática profissional em sua essência e estimular o desenvolvimento pessoal. Espera-se que ele dê conselhos, atuando também como guia e modelo. 
Nessa pós-graduação, o tutor tem ainda o importante papel de avaliar o médico residente, o que mostra a assimetria da relação estabelecida entre este e seu tutor ${ }^{65,66}$.

Mais recentemente, usa-se a expressão tutor pessoal (personal tutor) para designar aquele que, além de ensinar técnicas e habilidades, auxiliar na busca de conhecimentos e avaliar os alunos, também aconselha e oferece suporte. Essa denominação parece ter surgido exatamente para distinguir este profissional de outros já mencionados, aos quais se aplica o título de tutor, como também do profissional que auxilia exclusivamente no processo de aprendizagem $6,7,14,67$.

\section{Mentor}

Mentor é a designação dada a um profissional mais experiente, ao qual cabe guiar, orientar e aconselhar um jovem - a quem chamaremos "mentoreado" - no início de sua carreira. No processo de aprendizagem, a função do mentor pode ser considerada uma excelente ferramenta, que tem ação primordial ao longo do crescimento pessoal e profissional. O mentor tem um papel que ultrapassa a orientação para estudo e para "aprender a aprender", perseguindo não apenas os objetivos do curso, mas também assessorando o jovem na realização dos objetivos pessoais, investindo no desenvolvimento dos mais inexperientes e interessando-se por eles ${ }^{6,13,14,34}$. Estabelece uma relação complexa e multifacetada com o jovem profissional, buscando o desenvolvimento interpessoal, psicossocial, educacional e profissional. É uma relação de troca e de reciprocidade, que se firma por meio de um plano de desenvolvimento pessoal e na qual o ganho não é apenas unilateral, pois o mentor também aprende e cresce com a maneira de o jovem encarar a vida ${ }^{20,68-70}$.

Mentor (do latim mentor, oris, do antropônimo grego Mentor) é hoje aquele que serve como experiente conselheiro, como guia e sábio. É aquele que estimula, inspira, cria ou orienta idéias, ações, projetos e realizações. A palavra é derivada (por metonímia) de Mentor ${ }^{21,41}$, personagem da Odisséia, poema escrito por Homero no século VIII antes de Cristo. Esse poema conta a história do retorno do rei Ulisses (ou Odisseu) a sua terra, Ítaca, após a vitória na guerra de Tróia. Mentor é amigo e conselheiro do rei. Quando partiu para a guerra, Ulisses confiou sua mulher Penélope e seu filho Telêmaco a Mentor. Passaram-se 20 anos; a família de Ulisses está humilhada e cerceada pelos pretendentes ao trono de Ítaca. O poema mostra o desenvolvimento de Telêmaco e a importância de Mentor para o seu desenvolvimento ${ }^{71,72}$. Outro exemplo é encontrado na história do rei Artur, que foi educado por um mentor, Merlin ${ }^{73}$.

A função de mentor, que exprime a ação de pessoas mais maduras e experientes na vida e no exercício profissional, aconselhando, ensinando, instruindo e treinando os mais jovens e inexperientes, pode ser considerada histórica, pois acompanha a humanidade desde tempos imemoriais. Davidhizar ${ }^{74}$ afirma que também nas profissões consideradas modelares (pela concepção teórica hegemônica da sociologia das profissões, por primeiro reunirem as características definidoras da condição de profissão), como medicina e direito, a função de mentor é encorajada e considerada como excelente maneira de assistir os neófitos na profissão.

O uso contemporâneo do termo mentor tem origem nos Estados Unidos e foi motivado pelos empresários da década de 1970 pelo movimento feminista e pelo desenvolvimento das escolas de negócios nas universidades americanas ${ }^{9,17}$. Nessa área de negócios são escritos, então, vários artigos sobre a importância do mentor para o desenvolvimento especialmente da carreira de mulheres. Podemos questionar se isso não seria uma discriminação, subestimando o papel da mulher nesse meio. Depois o conceito migrou também para a área de formação do profissional de saúde, e a função tornou-se comum nas décadas de 1980 e 1990. Aparece principalmente em três áreas: no crescimento e desenvolvimento de adulto-jovens, no mundo dos negócios e nos cenários acadêmicos. Mas, devido à polissemia do conceito de mentor, não podemos afirmar que os autores querem dizer a mesma coisa quando usam o termo. Também não foi possível estabelecer uma unidade de pensamento que pudesse auxiliar no processo de escolha de mentores, nem no desenvolvimento de políticas para melhor organizar essa atividade. Como o mentor aparece cada vez mais como um integrante da formação profissional, é importante esclarecer seu significado, suas funções e o que se espera dele ${ }^{8,9,17,75}$.

O mentor é um profissional experiente, que desempenha a função de se responsabilizar por um jovem — recém-graduado ou graduando - e guia o caminho deste. Mas, para a aprendizagem de adultos, é imprescindível alto grau de autonomia para escolher o próprio modo e o próprio ritmo de aprender ${ }^{76,77}$. Podemos perguntar se a relação entre mentor e estudante, ou recémgraduado, não pode estimular a dependência, a passividade e o conformismo e ser um constrangimento ao desenvolvimento da autonomia do indivíduo. Segundo Schramm ${ }^{78}$, é preciso estar atento à definição de autonomia, que contém uma ambigüidade semântica entre o individual e o coletivo. $\mathrm{O}$ autor explica essa ambigüidade, explicitando um conteúdo ideal da autonomia (o agente moral como verdadeiro autor de suas ações: capacidade de autodeterminação) e um conteúdo de realidade (o ser humano vinculado a seus semelhantes, por meio de instituições legitimadas coletivamente: leis, normas, convenções e usos).

Então, nessa relação dialética, autonomia e heteronomia fazem parte de um conjunto complexo (diferente da concepção holística) cujos elementos são distinguíveis para evitar a confusão, mas inseparáveis para evitar o reducionismo ${ }^{78}$. A partir des- 
sa concepção, o mentor pode estimular a autonomia e não, ao contrário, reprimi-la. E ele pode fazer isso mostrando ao "mentoreado" o sentido crítico da autonomia moral ${ }^{78}$, que consiste em aliar o reconhecimento (mas não necessariamente a aceitação) das regras existentes à análise crítica e vigilante de eventuais preconceitos vigentes no imaginário social, responsáveis por histerias coletivas, discriminações e injustiças. Porém, alguns autores consideram que essa relação, que possibilita a autonomia, está mais ligada à função de facilitador e que essa função encontra melhor representação no conceito de preceptor e não no de mentor. Outros acreditam que a função de se responsabilizar por profissionais recém-graduados ou por estudante em treinamento se ajusta mais ao conceito de supervisor ${ }^{17,79}$.

A grande diferença da função do mentor é que ele não desempenha nem o papel clínico, nem o de avaliador. E, embora conheça as características do processo de ensino-aprendizagem, o mentor não baseia sua ação nelas, nem se preocupa exclusivamente com o desenvolvimento de habilidades clínicas. Segundo Armitage, ele tenta manter uma relação mais próxima e mais pessoal com o aluno ou com o recémgraduado9. Serve como guia e influencia as ações do jovem "mentoreado", influindo também na formação de sua personalidade, por meio do desenvolvimento da capacidade crítica desse jovem. O mentor deve ser capaz de ouvir o profissional em formação, suas posições, seus juízos e seus valores. Deve questioná-lo, buscando suas justificações e estimulando que o mais jovem desenvolva sua capacidade de raciocínio crítico. Aqui está a riqueza dessa relação bilateral, onde um cresce com o outro ${ }^{6,74}$.

Já nesse aspecto (raciocínio crítico), a função de mentor se relaciona com um dos conceitos essenciais do processo de aprendizagem, que é a reflexão. Refletir é analisar e avaliar uma ou mais experiências pessoais, generalizando determinado pensamento. Com isso o aprendiz se informa melhor, adquirindo mais habilidades e sendo mais efetivo que anteriormente. A reflexão na ação sempre envolve uma etapa analítica ("como faço algo?") e outra avaliativa ("o quão bem eu faço esse algo" $)^{69}$. Estimulando a reflexão, o mentor estará incentivando a habilidade de resolver problemas pessoais e profissionais, fazendo com que o mais jovem descubra ferramentas que o ajudem nesse processo de busca do conhecimento próprio e de sua independência.

Seguindo esse pensamento, sabemos que existe certo momento em que o jovem "mentoreado" adquire independência completa e pode "andar com suas próprias pernas". Mas como e quando o mentor deve saber que esse momento chegou? Aqui temos mais um ponto em comum com a relação entre pais e filhos, pois sempre chega um momento em que se "rompe o cordão umbilical", e os filhos podem caminhar sozinhos na vida ${ }^{73,79}$. A atividade do mentor se caracteriza, portanto, por uma mudança gradual, que vai desde a dependência quase completa do jovem no início da relação até a um aumento de independência e autonomia, que se tornam máximas no final dessa relação ${ }^{20,80}$. Achamos importante ficar atentos, nesse ponto, para que a ação do mentor não represente mais um fator que influencie e estimule a chamada adolescência prolongada ${ }^{81}$, representando um incentivo ao paternalismo.

Bellodi ${ }^{6}$, Spicer $^{69}$, Tobin ${ }^{82}$ e Larkin ${ }^{83}$ incluem, entre as funções do mentor, estimular o desenvolvimento ético e moral. $\mathrm{O}$ mentor permite que o jovem aprenda muito sobre o ambiente no qual está começando a entrar, assim como sobre prioridades, costumes, modelos e líderes, instituições e estruturas que fazem parte da vida profissional. Com isso, o mentor assume importante papel na trajetória pessoal e profissional do formando. Mas podemos considerar que atuar no desenvolvimento pessoal desse jovem profissional pode ser uma atividade que vai muito além do ofício de mentor. Este pode apresentar ao neófito as características, personagens, regras e normas, dificuldades e os mais variados caminhos do mundo do trabalho. Isso contribui para o desenvolvimento da identidade profissional do mais jovem. Mas, considerando que desenvolvimento pessoal e profissional se distinguem, embora não se separem, e que o último pode ser apenas um dos componentes do primeiro, acreditamos que o mentor deveria atuar apenas na parte profissional do desenvolvimento pessoal, o que não quer dizer que atue apenas na formação técnica.

As grandes mudanças que tanto a medicina como o ensino médico sofreram e continuam sofrendo suscitam dúvidas sobre se ainda é possível ou desejável a existência da função de mentor. O grande desenvolvimento científico, a crescente especialização, a fragmentação do conhecimento e a dificuldade de estabelecer relações mais próximas e duradouras entre professores e alunos modificaram o cenário da relação entre mentor e jovem profissional. Acredita-se, porém, que ainda é uma relação importante para a formação e para a profissionalização na medicina, que reforça o altruísmo e idealismo entre aqueles que estão se formando ou iniciando a atividade de médico. Isto porque cada geração oferece uma contribuição para a contínua evolução da prática e da ciência médicas por meio de suas próprias atividades e da educação e treinamento das gerações subseqüentes. E a atividade do mentor personifica essa contribuição e essa preocupação com os futuros profissionais ${ }^{68}$.

\section{CONCLUSÃO}

É notório que existem diversas congruências entre os termos aqui discutidos. Concordamos em que, muitas vezes, o profissional deve saber desempenhar as funções de preceptor, 
supervisor, tutor e mentor ao mesmo tempo, ou cada uma delas em momentos diferentes ${ }^{6,32}$. Percebemos, ainda, que esse desempenho simultâneo, ou sucessivo, das atividades ocorre com freqüência no ambiente de formação médica. Mas julgamos importante padronizar o uso das palavras, para termos certeza do que estamos falando ao utilizá-las. Esclarecer melhor o significado de cada termo e as funções que eles indicam pode contribuir para uma melhoria na formação médica e, conseqüentemente, na oferta de saúde à população. Então, com base principalmente em Mills ${ }^{8}$ e Bellodi ${ }^{6}$, mas também nos vários outros artigos consultados, queremos lançar uma proposta no intuito de tentar esclarecer e uniformizar a utilização desses termos no cenário da formação médica em nosso meio (Quadro 1).

O preceptor é o profissional que atua dentro do ambiente de trabalho e de formação, estritamente na área e no momento da prática clínica. Sua ação se dá por um curto período de tempo, com encontros formais que objetivam o progresso clínico do aluno ou recém-graduado. O preceptor desenvolve uma relação que exige pouco compromisso, percebido apenas no cenário do trabalho. Tem, então, a função primordial de desenvolver habilidades clínicas e avaliar o profissional em formação.

O supervisor é o profissional que tem sua atividade no ambiente de trabalho, mas que se encontra com o profissional em formação também fora da área e do momento de prática imediata. Sua atividade se estende por um período longo de tempo, que atravessa diferentes fases de interação. Os encontros geralmente são particulares, com pouca formalidade, e não objetivam apenas o progresso clínico do supervisionado: o supervisor mantém uma relação altamente compromissada (que idealmente deve se dar apenas durante as horas de trabalho, mas que pode exigir atividades extras), tendo como objetivo principal desenvolver o desempenho clínico como um todo, e não apenas as habilidades clínicas, permitindo ao supervisionado ser mais efetivo em seu trabalho. O supervisor tem ainda a função de avaliar como o mais jovem está desenvolvendo sua atitude profissional.

Já o mentor é aquele que se relaciona com o jovem "mentoreado" fora de seu ambiente imediato de prática profissional. Sua ação também se dá por um período longo de tempo e atravessa diferentes fases de interação. Os encontros podem ser coletivos ou particulares, confidenciais, com pouca formalidade, e não objetivam apenas o progresso clínico, numa relação de colaboração que exige alto grau de compromisso fora do cenário de prática e do ambiente de trabalho. Essa relação é assimétrica, porém não é hierárquica (nenhuma parte tem poder sobre a outra) e tem, então, os objetivos amplos de desenvolvimento pessoal e profissional, progressão na carreira, melhoria na prática clínica e no desempenho acadê- mico. É uma relação centrada menos nos problemas e mais nos desafios e tarefas cotidianas, características da fase de desenvolvimento pessoal e profissional na qual se encontra o jovem em formação. O mentor não tem a função de avaliador e, embora dê conselhos, possibilita ao mais jovem andar sozinho. O significado crucial do termo mentor está ligado à relação de suporte entre um profissional mais maduro e experiente, e outro, em formação ou recém-chegado à profissão. Esses dois profissionais, com diferentes idades, personalidades, estágios de vida e status profissional, desenvolvem, por certo período de tempo, uma relação que vai acrescentar conhecimentos e capacidade de tomada de decisões à história de ambos ${ }^{6,8,20,80,84}$.

Por fim, podemos apontar duas oportunidades de uso para o termo tutor em nosso meio: como substituto do termo mentor, em cenários onde seja preferível a este último, devido à inexistência de tradução para os termos mentorship e mentoring, em nossa língua, para designar a atividade exercida pelo mentor; ou ainda para designar as funções daquele que auxilia e estimula a "aprender a aprender" no cenário da Aprendizagem Baseada em Problemas.

Especificamente na residência médica, muito se tem discutido sobre competências essenciais que dêem maior efetividade ao processo de formação, melhorando os resultados dessa modalidade de pós-graduação. Além da redução das horas de trabalho dos médicos residentes, a principal recomendação é ter um profissional mais experiente que os acompanhe ${ }^{85}$. Esse profissional é aquele que ajuda o residente a perceber e reconhecer suas potencialidades e fraquezas profissionais e pessoais; e tem importante papel na escolha da especialidade a seguir e do caminho a ser percorrido pelo jovem profissional. Sua ação envolve a exploração das virtudes e vícios do neófito, e ajuda no discernimento da vocação e da missão profissional, auxiliando o jovem a encontrar seu lugar no mundo da medicina ${ }^{8,80,83,86}$.

Graças a essas características, a relação entre o mais jovem e o mais experiente é importante durante o processo de profissionalização ${ }^{87}$, incluindo o desenvolvimento de um corpo de conhecimentos e atitudes dos médicos. É importante sublinhar que não se pode confundir essa função com a de outros profissionais aos quais o jovem médico pode e deve ser encaminhado quando necessário: psiquiatra, psicólogo, psicopedagogo, assistente social e, até mesmo, algum religioso. O profissional experiente deve ser aquele que faz o jovem em formação honrar seus sonhos e pontos de vista. Ele pode trazer à tona o que o mais novo tem de melhor e ajudá-lo a desempenhar seu papel, mostrando que cada um é realmente importante no mundo em que vivemos ${ }^{8,20,83,84}$. 
QUADRO 1

Principais diferenças entre preceptor, supervisor, tutor e mentor

\begin{tabular}{|c|c|c|c|c|}
\hline Profissional & Principais papéis & $\begin{array}{c}\text { Principal local de } \\
\text { atuação }\end{array}$ & $\begin{array}{c}\text { Deve } \\
\text { avaliar? }\end{array}$ & Principais requisitos \\
\hline Preceptor & $\begin{array}{l}\text { - Ensinar a clinicar, por meio } \\
\text { de instruções formais e com } \\
\text { determinados objetivos e metas; } \\
\text { - Integrar os conceitos e valores da } \\
\text { escola e do trabalho. }\end{array}$ & $\begin{array}{l}\text { - Situações clínicas reais, } \\
\text { no próprio ambiente } \\
\text { de trabalho. }\end{array}$ & Sim & $\begin{array}{l}\text { - Conhecimento e habilidade em } \\
\text { desempenhar procedimentos clínicos; } \\
\text { - Competência pedagógica. }\end{array}$ \\
\hline Supervisor & $\begin{array}{l}\text { - Observar o exercício de determinada } \\
\text { atividade, zelar pelo profissional e ter } \\
\text { a certeza de que ele exerce bem sua } \\
\text { atividade; } \\
\text { - Atuar na revisão da prática } \\
\text { profissional. }\end{array}$ & $\begin{array}{l}\text { - Situações clínicas reais, } \\
\text { no próprio ambiente } \\
\text { de trabalho; } \\
\text { - Situações fora do } \\
\text { ambiente de trabalho. }\end{array}$ & Sim & $\begin{array}{l}\text { - Excelência no desempenho de } \\
\text { habilidade técnica profissional; } \\
\text { - Capacidade de proporcionar reflexão } \\
\text { sobre a prática diária do profissional. }\end{array}$ \\
\hline Tutor & $\begin{array}{l}\text { - Guiar, facilitar o processo de ensino- } \\
\text { aprendizagem centrado no aluno; } \\
\text { - Atuar na revisão da prática } \\
\text { profissional }\end{array}$ & - Ambientes escolares & Sim & $\begin{array}{l}\text { - Competência clínica e capacidade de } \\
\text { ajudar a aprender a aprender; } \\
\text { - Compreensão da prática profissional } \\
\text { em sua essência. }\end{array}$ \\
\hline Mentor & $\begin{array}{l}\text { - Guiar, orientar e aconselhar na } \\
\text { realização dos objetivos pessoais, } \\
\text { buscando o desenvolvimento } \\
\text { interpessoal, psicossocial, } \\
\text { educacional e profissional. }\end{array}$ & $\begin{array}{l}\text { - Fora do ambiente } \\
\text { imediato de prática } \\
\text { profissional. }\end{array}$ & Não & $\begin{array}{l}\text { - Capacidade de se responsabilizar, de } \\
\text { servir como guia, de oferecer suporte } \\
\text { e de estimular o desenvolvimento do } \\
\text { raciocínio crítico; } \\
\text { - Capacidade de ouvir, questionar e } \\
\text { estimular justificações. }\end{array}$ \\
\hline
\end{tabular}

\section{REFERÊNCIAS}

1. Macedo CG. Apresentação. In: Almeida M, Feuerwerker L, Llanos M, organizadores. A educação dos profissionais de saúde na América Latina. São Paulo: Hucitec/ Buenos Aires: Lugar Editorial/ Londrina: Ed. UEL; 1999. p. ix-xi.

2. Mattos MCI. Ensino médico: o que sabemos? Interface - Comunic, Saúde, Educ. 1997; 1:193-195.

3. Rebollo RA. Considerações sobre o estabelecimento da medicina no tratado hipocrático Sobre a arte médica. Scientia Studia 2003; 1(3): 275-937.

4. History of accreditation of medical education programs. JAMA 1983; 250(12): 1502-1508.

5. Rego S. A formação ética dos médicos: saindo da adolescência com a vida (dos outros) nas mãos. Rio de Janeiro: Editora FIOCUZ; 2003.

6. Bellodi PL, Martins MA. Tutoria: mentoring na formação médica. São Paulo: Casa do Psicólogo; 2005.

7. Cottrell DJ, McCrorie P, Perrin F. The personal tutor system: an evaluation. Med Educ 1994; 28 (6): 544-9.

8. Mills JE, Francis KL, Bonner A. Mentoring, clinical supervision and preceptoring: clarifying the conceptual definitions for Australian rural nurses. A review of the literature. Rural Remote Health 2005;5(3): 410.
9. Armitage P, Burnard P. Mentors or preceptors? Narrowing the theory-practice gap. Nurse Educ Today 1991; 11(3): 225-229.

10. Trindade CEP. O preceptor na residência médica em Pediatria. Jornal de Pediatria 2000; 76(5): 327-328.

11. Brasil. Ministério da Educação. Resolução CNRM 005 de 06 de junho de 2004. Disponível em: http: / / www.abramer.com. br/Pdf/cnrm_052004.pdf [Acesso em: 08 de março de 2007].

12. Jones A. Getting going with clinical supervision: an introductory seminar. J Adv Nurs 1998; 27: 560-6.

13. Freeman R. Faculty mentoring programmes. Med Educ 2000; 34:507-508.

14. Bellodi PL. O que é um tutor? Representações do papel em um grupo de professores de medicina durante o processo de seleção. Rev.Bras.Educ Méd. 2003; 27(3): 205-212.

15. Brad JW. The Intentional mentor: Strategies and Guidelines for the Practice of Mentoring. Prof Psychol Res Pr 2002; 33: 88-96.

16. Ramanan RA, Philips RS, Davis RB, Silen W, Reed JY. Mentoring in Medicine: Keys of Satisfaction. Am J Med 2001; 112: 336-341.

17. Morle KMF. Mentorship - is it a case of the emperor's new clothes or a rose by any other name? Nurse Educ Today 1990; 10(1): 66-69. 
18. Grealish L, Carroll G. Beyond preceptorship and supervision: a third clinical teaching model emerges for Australian nursing education. Aust J Adv Nurs 1997; 15(2): 3-11.

19. Cutcliffe JR; Lowe L. A comparison of North American and European conceptualizations of clinical supervision. Issues Ment Health Nurs 2005; 26(5): 475-88.

20. Stewart BM, Krueger LE. An Evolutionary Concept Analysis in Nursing of Mentoring. J Prof Nurs 1996; 12 (5):311-321.

21. Houaiss A, Villar MS. Dicionário Houaiss da Língua Portuguesa. Rio de Janeiro: Objetiva; 2001.

22. Goode WJ, Hatt PK. Métodos em pesquisa social. Tradução de Carolina M. Bori. São Paulo: Editora Nacional; 1979.

23. Lyth GM. Clinical supervision: a concept analysis. J Adv Nurs 2000; 31(3): 722-729.

24. Rodgers BL. Concepts, analysis and the development of nursing knowledge. J Adv Nurs 1989; 14: 330-335.

25. Pitkin HF. Representação: palavras, instituições e idéias. Lua Nova 2006; 67: 15-47.

26. Ortiz R. As ciências sociais e o inglês. RBCS 2004; 19(54): 5-22.

27. Ryan-Nicholls K. Preceptor recruitment and retention. Can Nurse 2004; 100 (6): 19-22.

28. Bain L. Preceptorship: a review of the literature. J Adv Nurs 1996; 24(1): 104-107.

29. Stuart MR, Orzano AJ, Eidus R. Preceptor development in residency training through a faculty facilitator. J Fam Pract 1980; 11(4): 591-595.

30. Burns C, Beauchesne M, Ryan-Krause P, Sawin K. Mastering the preceptor role: challenges of clinical teaching. J Pediatr Health Care 2006; 20(3):172-183.

31. Obermeyer MV. Are you a culturally competent preceptor. Nursing 2006; 36(6): 54-55.

32. Ricer RE. Defining preceptor, mentor and role model. Fam Med 1998; 30 (5): 328.

33. Beckett C, Wall M. Role of the clinical facilitator. Nurse Educ Today 1985; 5: 259-262.

34. Beauchesne MA, Howard EP. An investigation of the preceptor as potential mentor. Nurse Pract 1996; 21 (3): 155-159.

35. Stuart-Siddal S, Haberlin JM. Qualities that make a preceptor. RNABC News 1985; 17 (4): 28.

36. Quill TE. A cross-sectional study of the influence of the ambulatory preceptor as a role model. Arch Intern Med 1987; 147: 971-973.

37. Burke LM. Preceptorship and pos-registration nurse education. Nurse Educ Today 1994; 14: 60-66.

38. Siegel BS. A view from the residents: effective preceptor role modeling is in. Ambul Pediatr 2004; 4(1): 2-3.
39. Pierce J, Paulman A. The preceptor as ethic educator. Fam Med 1999; 31(10): $687-688$.

40. Wright SM, Kern DE, Kolodner K, Howard DM, Brancati FL. Attributes of excellent attending physician role models. NEJM 1998; 339(27): 1986-1993.

41. Oxford Advanced Learner's Dicitionary of Current English. Oxford; Oxford University Press; 2000.

42. Cordeiro LL. Relações industriais versus supervisão. RAE 1968; 8 (28): 95-112.

43. Stokoe B, McClarey M. Safety measures. Nursing times 1995; 91(26): 30-31.

44. Sloan G. Clinical supervision: beginning the supervisory relationship. BJN 2005; 14 (17): 918-923.

45. Wood J. Clinical supervision. Br J Perioper Nurs 2004; 14(4): 151-156.

46. Kilminster SM, Folly BC. Effective supervision in clinical practice settings: a literature review. Med Educ 2000; 34:827-840.

47. Médica: os estágios extracurriculares em questão [dissertação]. Rio de Janeiro: Instituto de Medicina Social, Universidade Estadual do Rio de Janeiro; 1994.

48. General Medical Council. The New Doctor - Recommendations on General Clinical Training. London: General Medical Council; 2005. Disponível em: http:/ /www.gmcuk.org [Acesso em: 25 de Outubro de 2006].

49. Wright B. Clinical supervision. Accid Emerg Nurs 1993; 1: 181-182.

50. Goorapah D. Clinical supervision. J Clin Nurs 1997; 6(3):173-178.

51. Yegdich T. Clinical supervision and managerial supervision: some historical and conceptual considerations. J Adv Nurs 1999;30(5):1195-1204.

52. Berggren I, da Silva AB, Severinsson E. Core ethical issues of clinical nursing supervision. Nurs. Health Sci 2005; 7: 21-28.

53. Severinsson E. Ethics in clinical nursing supervision-an introduction to the theory and practice of different supervision models. Collegian 1999; 6: 23-28.

54. Berggren I, Severinson E. The influence of clinical supervision on nurses' moral decision-making. Nurs. Ethics 2000; 7: 124-133.

55. Berggren I, Bégat I, Severinsson E. Australian clinical nurse supervisors' ethical decision-making style. Nurs. Health Sci.2002; 4: 13-21.

56. Yegdich T. How not to do clinical supervision in nursing. J Adv Nurs 1998; 21(1): 193-202.

57. Van Oijen E. Supervision: whipping up a storm. Nurs Stand 1994; 9(8):48.

58. Dolmans DHJM, Luijk SJV, Wolfhagen IHAP, Scherpbier AJJA. The relationship between professional behaviour 
grades and tutor performance ratings in problem-based learning. Med Educ 2006; 40: 180-186.

59. Maudsley G. Roles and responsibilities of the problem based learning tutor in the undergraduate medical curriculum. BMJ 1999; 318: 657-661.

60. Wetzel MS. Developing the role of the tutor / facilitator. Postgrad Med J 1996; 72(850): 474-477.

61. Quintanilha MMS. A educação de D. Pedro II, Imperador do Brasil. [Apresentação ao Seminário Pesquisa do PPE; 1994; Universidade Estadual de Maringá, Maringá,Brasil .p.1-9].

62. Caestecker J. Role of the clinical tutor. Postgrad Med J 2002; 78: 639-640.

63. National Association of Clinical Tutors. Generic core job. [Documento da internet] 1999 Nov. [postgraduate clinical tutor/director of PGME]. Disponível em: http://www. nact.org.uk/ point to [Documents and then to Generic Core Job Plan] [Acesso em: 25 de Outubro de 2006].

64 . Holden J. Randomized controlled trial of general practitioner tutor visit or mailing to encourage general practicebased education. Med Educ 2001; 35(10): 938-940.

65. Llamas JS. The Manual of the Primary Care Tutor. Aten Primaria 1996; 17 (3): 177-178.

66. Llamas JS, Hernández ML. Docencia posgrado: factores condicionantes de la relación tutor-residente en medicina familiar. Aten Primaria 1997; 20 (9): 511-518.

67. Gidman J. The role of the personal tutor: a literature review. Nurse Educ Today 2001;21(5):359-365.

68. Barondess JA. On mentoring. J R Soc Med 1997; 90(6): 347349.

69. Spicer R. Mentoring and personal development planning in postgraduate dental education: a review. Dent Update 2004; 31(8):472-4, 477-480.

70. Merriam S. Mentors and protégés. A critical review of the literature. Adult Educ Quarterly 1983; 33(3):161-173.

71. Homero. A Odisséia (em forma de narrativa). Rio de Janeiro: Ediouro; 1999. [Tradução de Fernando C. de Araújo Gomes]

72. Fénelon FSM. As aventuras de Telêmaco: filho de Ulisses. São Paulo: Madras; 2006. [Tradução de Maria helena C. V. Trylinski]

73. Massie A. Rei Artur. Rio de Janeiro: Ediouro; 2004. [Tradução de Laura Alves e Aurélio B. Rebello]

74. Davidhizar RE. Mentoring in doctoral education. J Adv Nurs 1998; 13: 775-781.

75. De Marco R. Mentorship: a feminist critique of current research. J Adv Nurs 1993; 18(8): 1242-1250.
76. Brandão C. O que é o método Paulo Freire. São Paulo: Editora Brasiliense; 1981.

77. Freire P. Educação como prática de liberdade. Rio de Janeiro: Paz e Terra; 1976.

78. Schram FR. A autonomia difícil. Bioética 1998; 6(1):27-37.

79. Rolfe G. The role of clinical nurse supervision in the education of student psychiatric nurses: a theoretical approach. Nurse Educ Today 1990; 10 (3): 193-197.

80. Pellegrini Junior VD. Mentoring during residency education: a unique challenge for surgeon? Clin Orthop Relat Res 2006; 449:143-148.

81. Câmara MM, Cruz AR. Adolescência prolongada: o tempo que não se quer deixar passar. Educar em Revista 2000; 15. Disponível em: http://www.educaremrevista.ufpr.brarquivos_15camara_cruz.pdf. [Acesso em: 21 de Dezembro de 2006].

82. Tobin MJ. Mentoring: seven roles and some specifics. Am J Respir Crit Care Med 2004; 170(2): 114-117.

83. Larkin GL. Mapping, Modeling, and Mentoring: Charting a Course for Professionalism in Graduate Medical Education. Cambridge Quarterly of Healthcare Ethics 2003; 12: 167-177.

84. Nedd N, Nash M, Galindo-Ciocon D, Belgrave G. Guidede growth intervention: from novice to expert through a mentoring program. J Nurs Care Qual 2006;21(1):20-23.

85. Ramanan RA, Taylor WC, Davis RB, Phillips RS. Mentoring and Career Preparation in Internal Medicine Residency Training J Gen Intern Med 2006; 21:340-345.

86. Tsai JC, Lee PP, Chasteen S, Taylor RJ, Brennan MW, Schmidt GE. Resident physician mentoring program in ophthalmology: the Tennessee experience. Arch Ophthalmol 2006; 124: 264-267.

87. Sambunjak D, Straus SE, Marusic A. Mentoring in academic medicine - a systematic review. JAMA 2006; 296(9): 1103-1115.

\section{CONFLITOS DE INTERRESE}

Declarou não haver

\section{ENDEREÇO PARA CORRESPONDÊNCIA}

Sérgio Henrique de Oliveira Botti

Hospital Universitário da Universidade Federal de Juiz de Fora

Rua Catulo Breviglieri, s/n $\mathrm{n}^{\circ}$ - Santa Catarina

36036-110 - Juiz de Fora - MG

E-mail: botti@uai.com.br 